\title{
MIDAS
}

Museus e estudos interdisciplinares

$4 \mid 2014$

Varia e dossier temático: "Museus, utopia e urbanidade"

\section{Reflexões sobre diversidade de representações, de públicos e de estratégias interpretativas}

Reflexions concerning the diversity of representations, publics and interpretative strategies

\section{Andreia Vale Lourenço}

\section{OpenEdition}

\section{Journals}

\section{Edição electrónica}

URL: http://journals.openedition.org/midas/664

DOI: $10.4000 /$ midas.664

ISSN: 2182-9543

Editora:

Alice Semedo, Paulo Simões Rodrigues, Pedro Casaleiro, Raquel Henriques da Silva, Ana Carvalho

\section{Refêrencia eletrónica}

Andreia Vale Lourenço, «Reflexões sobre diversidade de representações, de públicos e de estratégias interpretativas », MIDAS [Online], 4 | 2014, posto online no dia 06 fevereiro 2015, consultado no dia 30 abril 2019. URL : http://journals.openedition.org/midas/664 ; DOI : 10.4000/midas.664

Este documento foi criado de forma automática no dia 30 Abril 2019.

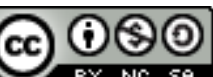

Midas is licensed under a Creative Commons Attribution-NonCommercial-ShareAlike 3.0 International License 


\title{
Reflexões sobre diversidade de representações, de públicos e de estratégias interpretativas
}

\author{
Reflexions concerning the diversity of representations, publics and \\ interpretative strategies
}

Andreia Vale Lourenço

\section{NOTA DO EDITOR}

Artigo recebido a 01.04.2014

Aprovado para publicação a 30.12.2014

\section{Introdução}

1 Este artigo consiste numa reflexão sobre os públicos dos museus e sobre o seu relacionamento com as formas de representação que têm lugar na instituição, refletindo, também, sobre as estratégias de interpretação que ocorrem no processo de visita. Importa também esclarecer que o texto nasce da investigação para a dissertação de doutoramento sobre públicos, tendo como caso de estudo o Museu da Cidade de Aveiro, focando os processos de construção da motivação para a visita. O trabalho de investigação é, neste caso, um processo implicado, pois a investigadora e a mediadora na instituição em estudo são a mesma pessoa. Neste âmbito, a investigação procura conduzir-se pela abordagem construtivista e colaborativa, mas também baseando-se na prática reflexiva. 0 artigo é fruto da investigação bibliográfica e do estabelecimento das questões e do plano de investigação, no âmbito do projeto de doutoramento, por um lado, e da intuição profissional, por outro. Se as leituras efetuadas e sessões de doutoramento e orientação conduziram a um novo olhar sobre a instituição caso de estudo, não é menos verdade que 
a imersão como técnica do museu, com funções de mediação, significou, igualmente, uma necessidade maior de procurar compreender como o contexto contemporâneo influencia o universo museológico, de como as representações e a narrativa do museu se relacionam com o processo de interpretação do visitante, bem como as sempre presentes questões de quem visita o museu e porquê. Para cada linha de reflexão, o artigo, procura expor e relacionar a posição de diversos autores.

2 Atualmente, o campo de saber museológico que se prende com os estudos de públicos e o conhecimento dos públicos dos museus encontra-se em rápido desenvolvimento, salientando-se a presença de um sentimento de urgência e importância derivado do debate sobre o usufruto social da cultura. $O$ debate tem vindo a trazer a lume questões vitais sobre a posição e a função dos museus na sociedade atual, destacando-se que, progressivamente, se constata que a discussão deve ser enriquecida com as perspetivas e opiniões dos seus visitantes (Hooper-Greenhill 2006).

3 As novas formas de pensar as audiências procuram traduzir o caráter da relação entre museus e públicos, que se quer dinâmica, através da implementação de estratégias pedagógicas e comunicacionais diversificadas, reconhecendo a multiplicidade de características sociais existentes atualmente, bem como atendendo às atitudes culturais dos diversos públicos. Os museus contemporâneos procuram, deste modo, colocar no topo das prioridades a interpretação das coleções e a constante necessidade de partilhar e reinterpretar as mesmas com os visitantes.

4 Qualquer tentativa de reflexão neste âmbito, relacionada, em certa medida, com o papel, a função e o potencial de intervenção dos museus, carece de definição de alguns conceitoschave, nomeadamente, "património", "comunidade" e "representação". A este nível, no artigo, considera-se património todos os objetos ou grupos de objetos, materiais ou intangíveis, que são coletivamente reconhecidos ou apropriados pelo seu valor como memória histórica, resultando na necessidade sentida de proteção, preservação e comunicação. Esta conceção refere-se a todos os bens naturais ou resultantes da ação humana, tanto tangíveis como imateriais, sem restrições de espaço ou tempo. Considerase o património como um bem público, cuja preservação deve ser assumida e sentida pela comunidade. Neste âmbito, como será exposto, o conceito de comunidade relaciona-se diretamente com a problemática do património, sendo inclusivamente questionado se o património constrói a comunidade, ou se o contrário tem lugar.

5 O conceito de comunidade não é passível de simplificação, e, se num primeiro olhar, pode ser confundido com a definição de sociedade, assumida como uma comunidade estruturada por instituições, logo nos apercebemos que a noção de comunidade pode ser bem mais complexa. Nesta abordagem refletiva, o conceito de comunidade traduz um conjunto de pessoas que vivem coletivamente ou assumindo uma associação/ligação e, principalmente, que partilham um conjunto de elementos estruturadores como, por exemplo, a linguagem, a religião ou os costumes, sem estarem necessariamente reunidas em torno de estruturas institucionais.

6 Tanto a definição de património, como de comunidade conduzem-nos, também, à problemática da representação. Nesta abordagem, representação significa o espaço entre as coisas, os objetos, por exemplo, e as formas de os conceptualizar. Manifesta, mais concretamente, a tentativa de introduzir nos museus elementos passíveis de representar os modos de ver e compreender o mundo inerentes a grupos sociais específicos. Neste sentido, a representação correlaciona-se com o conceito de interpretação e de exposição, 
possibilitando o desenvolvimento de narrativas expositivas baseadas em ideias e histórias.

70 artigo também procura ponderar os públicos dos museus, no sentido em que se considera como "público" toda a extensão de população a quem o museu se dirige, representando um universo potencialmente maior que o dos visitantes, neste caso sinónimo de utilizadores.

\section{Museus, uma reflexão sobre o seu contexto}

$8 \mathrm{Na}$ atualidade, qualquer tentativa de reflexão sobre os museus insere-se no campo de saber mais abrangente da teoria cultural contemporânea, envolvendo a análise da cultura no seu sentido mais amplo, tanto da cultura como modo de vida, como a cultura enquanto resultado de práticas estéticas (ex. pintura ou música). Influenciada pelo relativismo pósmoderno, a teoria cultural contemporânea tende a analisar a cultura sob uma perspetiva pluralista. Isto significa que se estudam culturas e não Cultura e que, frequentemente, são focadas as diferenças culturais e, neste âmbito, os museus surgem como um campo de interesse, pois tratam-se de instituições que ativamente procuram expor múltiplas culturas.

9 A pós-modernidade, de um modo geral, tem sido definida como um período de mudança e de alteração social que se contextualiza com o fim da sociedade industrial e que conduz a uma divisão e reorganização do poder político e económico, resultado do surgimento de novas identidades políticas e sociais. O desenrolar dos processos sociais e económicos, relacionados com fenómenos como o desenvolvimento dos meios de comunicação e de transporte, associados ao crescimento exponencial das cidades, ao êxodo rural e a fluxos populacionais transnacionais de dimensão significativa, levaram a um redimensionamento do mundo, em que o espaço e o tempo deixaram de constituir limitações na organização do quotidiano. Nesta conjuntura, os indivíduos libertam-se dos constrangimentos espaciais e temporais, que constituíam fatores de orientação coletiva e individual, produzindo-se uma realidade que se pauta por uma «ausência de temporalidade nos produtos, nos valores e nas relações sociais» (Anico 2005, 72).

O âmbito dos objetos culturais, as experiências e as práticas rotuladas de pós-modernas é bastante diversificado... temos a música, a arte, a ficção, o cinema, o drama, a fotografia, a arquitetura, a teoria e a crítica literárias, a filosofia, a antropologia, a sociologia, a geografia... Este tipo de mudança começou a ser notada nos trabalhos de Jean Baudrillard (1983) e de Jean-François Lyotard (1984) e gerou uma série de derivativos do termo pósmoderno, uma família de designações que inclui a pós-modernidade, a pós-modernização e o pós-modernismo, por vezes, de utilização confusa e variável. Baudrillard aponta como fundamentais as novas formas de tecnologia e de informação, bem como a sua centralidade e papel na transformação de um sistema social produtivo para um reprodutivo, no qual as simulações e os modelos organizam o mundo, confundindo a distinção entre o real e a aparência. Lyotard, por sua vez, menciona a sociedade pósmoderna para explicar as transformações no sentido de uma ordem pós-industrial. Este autor, interessado especificamente pela «informatização da sociedade», aponta a substituição do saber narrativo por uma pluralidade de jogos de linguagem e do universalismo pelo localismo, quase que traduzindo a pós-modernidade como um novo «estado de espírito» (Lyotard 1986-87, 209). 
11 Este contexto conduz a que nostalgia e património se encontrem, por vezes, associados. David Lowenthal refere-se a este sentimento como o «mal-estar moderno» (Lowenthal 2003, 4), originado por períodos de rápida mudança e que se caracteriza como uma reação à suposta perda de valores e de referências culturais do passado. Marc Guillaume (2003, 39) associa este sentimento a um «verdadeiro trabalho de luto relativamente a um mundo em irreversível desaparecimento». A resistência ao ritmo da mudança contemporânea poderá ter sido um dos fatores que conduziu a um aumento generalizado da atração pelo passado e à proliferação de museus. Os museus, neste âmbito, constituem-se também como exercícios de rememoração das práticas culturais há muito desaparecidas, mas que, ao serem conservadas e transmitidas, passam a constituir aquilo que Guillaume designa por «álibis do esquecimento» $(2003,40)$.

12 No âmbito da reflexão sobre os museus, mais concretamente sobre a diversidade de representações, de públicos e de estratégias interpretativas, a definição de pósmodernidade interessa no sentido em que se pretende chamar a atenção para as mudanças que tiveram lugar na cultura contemporânea em termos de alterações nos modos de teorização, apresentação e divulgação de trabalhos de caráter artístico, intelectual e académico. Em simultâneo, destacam-se as mudanças mais amplas na esfera cultural envolvendo os modos de produção, consumo e circulação dos bens simbólicos, que, por sua vez, podem articular-se e relacionar-se com as transformações ocorridas nos equilíbrios de poder e nas interdependências entre os grupos e as frações de classe em ambos os níveis, intra e intersocietais. Também é relevante refletir sobre as mudanças nas práticas quotidianas que, na sequência do abordado, deram lugar a diferentes formas de sistemas de significação e a novos meios de orientação e estruturas de identidade (Featherstone 1990, 104).

13 Neste contexto, Zygmunt Bauman sugere que o presente período de «tardia», «alta», «líquida» ou «pós» modernidade se caracteriza por incontáveis e incompletos processos de modernização, marcados pela ausência de temporalidade nos produtos, nos valores e nas relações sociais, aos quais o campo cultural não é alheio (Bauman 2000, 28). Este cenário conduziu a profundas transformações no relacionamento dos museus com os seus visitantes, cada vez mais percecionados como consumidores ativos da oferta cultural dos museus e, estes últimos, progressivamente transformados em centros de informação (Anico 2005, 4).

14 O conceito de "pós-museu", neste cenário, traduz um conjunto de novas conceções que assinalam o avanço para um futuro positivo e otimista para os museus, visto que uma das suas dimensões se prende com uma compreensão mais aberta do complexo relacionamento entre cultura, comunicação, aprendizagem e identidade, permitindo uma nova abordagem às audiências do mesmo (Hooper-Greenhill 2007). Um segundo aspeto, igualmente relevante, liga-se com a promoção de uma sociedade mais justa e equitativa, defendendo-se que a cultura trabalha para representar, reproduzir e constituir identidades e que este facto acarreta um sentido de responsabilidade ética e social.

Neste âmbito e considerando o acima exposto, a reflexão sobre as formas de representação e os públicos de um museu, leva-nos a considerar a renovação das filosofias e das práticas museológicas que têm conduzido os museus a assumirem um papel social, cada vez mais central, nas suas abordagens. Do mesmo modo, estamos perante um reconhecimento crescente da centralidade da cultura em relação às questões de identidade, ponderando-se o significado da representação e o poder dos símbolos e objetos enquanto veículos de significados, com o potencial de materializar identidade e o 
poder de invocar alinhamentos culturais e sociais (Hooper-Greenhill 2007). A este nível, também importa refletir sobre a interpretação no sentido de que se trata de uma prática radicada nas relações sociais e que os processos interpretativos, constituindo-se como parte do imaginário cultural, não podem ser percebidos ou percecionados como neutrais.

\section{Reflexão sobre a procura de conhecimento sobre os públicos dos museus}

16 Os estudos de públicos em museus devem ser considerados sob uma perspetiva multidisciplinar, dada a sua metodologia, a diversidade das suas fontes teóricas e a amplitude das variáveis estudadas. De um ponto de vista metodológico, os estudos de públicos utilizam técnicas de recolha de dados provenientes de diversas disciplinas, fundamentalmente das chamadas ciências sociais, nomeadamente da psicologia, da economia, da antropologia e da sociologia. Por outro lado, os trabalhos realizados no âmbito dos estudos de públicos partiram, frequentemente, de elaborações teóricas provenientes de outras disciplinas, procurando demonstrar a sua aplicação ao contexto dos museus. Igualmente, as teorias da educação não formal têm sido utilizadas para explicar as condições e os resultados da aquisição de conhecimentos através de conteúdos expositivos, enquanto que os princípios sobre os diversos estilos de ócio da psicologia social parecem ajudar e clarificar as questões levantadas sobre a motivação dos visitantes para a frequência dos museus.

17 Atualmente, a investigação sobre os públicos constitui quase que uma obrigação e os museus operam num mundo saturado de estatísticas e informações emanadas por instituições oficiais e por estudos de mercado comerciais. A circulação de informação entre as ciências sociais e os museus reflete novas formas de poder e conhecimento, e é indicativa de uma instituição que necessita de se adaptar constantemente à mudança e da qual se exige uma reflexão constante sobre os resultados das suas ações. De certa forma, o museu interiorizou o campo da investigação social (Fyfe 2006, 43).

18 Neste contexto, verifica-se que os últimos 50 anos significaram uma profunda mudança no relacionamento dos museus com as suas audiências. Na década de 1960, o relacionamento podia-se caracterizar como simples e unidimensional, com os museus a desempenharem o papel de autoridade poderosa e incontestada. Os funcionários dos museus percecionavam o seu público como um reflexo de si próprios, conhecedores dos significados das coleções e do «valor» óbvio que detinham para a sociedade. Assim, os museus acreditavam que o seu público eram aqueles que o visitavam regularmente e que compreendiam as regras e definições segundo as quais as coleções eram constituídas e interpretadas (Reeve e Woollard 2006, 5). Contudo, as últimas cinco décadas trouxeram o reconhecimento por parte dos museus da diversidade do seu público, efetivamente constituído por grupos diferenciados, interessados em articular as suas necessidades e expressar as suas opiniões, podendo exercer, por exemplo, a opção de não visitar o espaço. Do mesmo modo, os museus têm vindo a apreciar, se bem que ainda não totalmente, a complexa relação que pode ser formada por vários indivíduos que tomaram um papel ativo na contribuição em várias das atividades museológicas.

19 A crescente tomada de consciência do poder da cultura, conduziu a questões sobre a sua utilização e sobre a participação cultural, bem como sobre a subjetividade e significado da cultura. Os museus são ativos na formação do conhecimento, através das suas coleções 
encenam narrativas visuais que fornecem perspetivas do passado e, consequentemente, do presente. Nas exposições, os museus «condensam, deslocam, reorganizam (ficcionam) e mitificam» (Thistlewood 1993, 193). Verifica-se que as exposições combinam diversos artefactos e fragmentos da cultura material numa narrativa coerente, contínua e unificada. Para tal, os museus, inevitavelmente, selecionam a partir das coleções o que pode ser exposto, e esta seleção molda a narrativa visual apresentada, em que diferentes contextos de significado são invocados mediante os diferentes conjuntos produzidos.

Interessa, igualmente, atentar à terminologia utilizada para descrever todos aqueles que utilizam e contribuem para os museus, visto que esta permite abordar uma série de ideias-chave expressas através de vários autores e textos e que tem influenciado, direta ou indiretamente, a mudança de paradigma no relacionamento museu/audiência. A audiência do museu tem sido relatada como: visitantes, público, utilizadores, audiência, consumidores, participantes...

21 De acordo com Reeve e Woollard (2005), as implicações na seleção de um termo ou outro são reveladoras: os museus necessitam de reconhecer que oferecem continuamente produtos de consumo, tais como exposições, e, no entanto, para a maioria dos profissionais, a designação "consumidor" coloca-o lado a lado com centros comerciais. Já a denominação "público" engloba todos aqueles que são considerados significativos para o museu, mesmo que não necessariamente o visitem. Neste âmbito, é também interessante notar que existe uma certa preferência por utilizador e frequentante em vez de "não-visitante" ou "não-público". Deste modo, a utilização destes termos (audiência, visitante...) traduz diferentes relacionamentos dos museus com o seu público. A "audiência" é considerada mais passiva que os "participantes", e o termo "visitante" sugere menor autoridade e exigência que o "consumidor". Aos olhos dos museus, a definição de consumidor e suas implicações poderá significar um novo equilíbrio de poder a favor deste último o que implica uma mudança na lógica dos museus enquanto instituições culturais (Reeve e Woollard 2006, 6).

22 Neste contexto, Jean Davallon (2003) defende a necessidade de se entender por público, um conjunto de indivíduos dotados de uma competência específica, capazes de emitir opiniões e debater conceitos. A emergência deste "público cultural", frequentador de exposições e museus, exige uma nova estruturação do espaço museológico e uma redefinição das suas missões. João Teixeira Lopes e Bárbara Aibéo também destacam a importância de «questionar as condições que agregam as pessoas num determinado público, bem como o facto de esse público ser mais do que o somatório dos indivíduos que nele se agrupam». Como estes autores reforçam: «não se constrói um público num vazio comunicacional (...). Os públicos existem em torno de uma tríade fundamental que reúne a criação, a difusão e a receção culturais contextualizadas» (Teixeira Lopes e Aibéo 2007, 54).

Susan Pearce reconhece que partindo da cultura material dos objetos, o binómio públicomuseu encontra o seu sentido na exposição e na difusão, veículos de comunicação e diálogo entre o visitante e as coleções. Sob esta perspetiva, os museus constituem-se como verdadeiros centros de investigação dos públicos (Pearce 1992). Simultaneamente, a exposição pode ser compreendida como uma «tecnologia da imaginação» (Macdonald 1996, 269), um local organizado no qual os visitantes podem reforçar ou reconstruir os seus conhecimentos, pois a exposição combina elementos sensoriais e cognitivos de forma articulada, que os visitantes abordam através da sua própria experiência. Este processo pressupõe, contudo, que os profissionais dos museus abandonem o conceito do visitante 
passivo, mero recetor do conhecimento a disseminar, e o aceitem como sujeito ativo que aborda os museus com o seu contexto individual.

Outra perspetiva passa pela questão: quem visita os museus? São muitos os fatores que influenciam quem visita e quem não visita os museus. Mesmo antes de entrarem, várias pessoas sentem que a experiência de visita não é para elas. Este sentimento foi descrito por Elaine Gurian $(2005,203)$ como «o medo de transpor» a entrada dos museus, que se reveste de características físicas e psicológicas. Na realidade, segundo a autora, frequentemente, a arquitetura dos espaços museológicos impede-os de se tornarem na desejável «nova praça da cidade» (Gurian 2006, 53), ou num espaço comunitário neutro, que permita a mais pessoas sentirem-se bem-vindas e confiantes.

No âmbito da reflexão sobre os museus importa, também, ponderar a sua relação com os turistas. Nelson Graburn $(2007,129)$ considera os turistas como um grupo de visitantes que os museus tradicionalmente procuram atrair e cujas necessidades podem, por vezes, ultrapassar as da comunidade local. Entre os turistas e a comunidade local existem aspetos complementares, mas também subsistem alguns elementos em que as expectativas dos turistas competem com os interesses dos habitantes, gerando-se a necessidade de definir quais as obrigações dos museus perante a sua audiência de turistas.

Os turistas possuem as suas próprias agendas e o seu comportamento tem uma lógica própria que influencia as suas decisões. Vários estudos demonstram que existe um perfil sociodemográfico comum entre os turistas consumidores de cultura e os visitantes regulares de museus, que se articulam com motivações relacionadas com a aprendizagem, o entretenimento e a sociabilização. Os turistas também se encontram num contexto distinto do quotidiano e das suas vivências habituais, estando, por isso, mais disponíveis e predispostos para este tipo de atividade. A este nível, pode fazer algum sentido tratá-los como um segmento de público diferenciado dos visitantes locais (Graburn 2007).

Também é relevante, no contexto dos museus, refletir sobre os motivos para a frequência dos espaços. Os fatores de socialização, os hábitos e as atitudes familiares e os interesses relacionados com as coleções ou com o tema do museu, concorrem para a decisão de visita. Também parece existir uma aliança entre o caráter educativo e de entretenimento patente nos museus atuais. John Falk, em Identity and the Museum Visitor Experience, avança a hipótese dos visitantes frequentes se caracterizarem por possuírem uma atenção especial ao conteúdo do museu, bem como defende que os visitantes que já conhecem algo sobre a temática em exposição alcançam maiores benefícios educativos da visita (Falk 2009, 26). Neste âmbito, a definição de visitante frequente tem variado consoante os autores, abrangendo entre aqueles que visitam museus três ou mais vezes por ano, até a um mínimo de sete visitas por ano para o visitante se integrar na categoria de visitante frequente. Independentemente deste aspeto da definição, os visitantes regulares caracterizam-se por um interesse e conhecimento na temática do espaço museológico em questão.

Por um lado, dispomos, atualmente, de uma grande quantidade de informação disponível sobre as formas de utilização dos museus e galerias de arte, da qual se pode extrair uma série de ideias gerais sobre a problemática, contudo, também se constata que não é fácil obter uma imagem global sobre os modos como se efetuam as visitas, nem é possível generalizar dados provenientes de diferentes trabalhos de investigação, pois várias investigações parecem fornecer resultados contraditórios e muitas abordam questões relacionadas com objetivos muito concretos (Hooper-Greenhill 2006). Simultaneamente, 
existem diversas técnicas de investigação e cada uma delas gera um determinado tipo de informação.

\section{Reflexão sobre as estratégias de interpretação dos visitantes que têm lugar nos museus}

29 A cultura, o património e os museus constituem-se como elementos centrais nas agendas políticas, face à sua capacidade de definir, celebrar e também de questionar a identidade cultural de grupos sociais. Este pressuposto aplica-se com particular relevância aos museus municipais, podendo referir que a exposição do património local, nestes museus, pode resultar num discurso fragmentado e híbrido, composto por uma narrativa expositiva que procura contrastar diferentes momentos históricos de forma distinta e em separado (Anico 2009, 64). As ideias e os valores patentes nos museus locais atuam, frequentemente, como uma estratégia protetora, promovendo um paradigma de identidade primordial, baseado na existência de uma comunidade local mitificada e na visão de um passado único, pleno de autenticidade, solidariedade e distinção.

30 Não nos podemos esquecer que o património se constitui como uma construção simbólica e ideológica, submetida a influências da esfera histórica, política e social, no seio das quais os significados culturais são produzidos e interpretados. Neste âmbito, o discurso sociocultural emerge de forma fundamentada nos referenciais culturais, com a capacidade de produzir e reforçar um sentimento partilhado de ligação e pertença a um local, tempo ou comunidade. As práticas culturais e, por exemplo, as exposições, bem como as coleções e a documentação de fragmentos da cultura material convertem-se em estratégias concebidas para informar as pessoas dos legados culturais.

31 Vários museólogos, entre os quais Rhiannon Mason (2006), defendem que o significado dos objetos é inseparável do seu contexto de exposição e são sujeitos à interpretação pelos visitantes. Neste cenário, a importância do contexto histórico sai reforçada, chamando-se a atenção para a natureza plural e construídas das "histórias". Os museus contribuem para a compreensão destas perspetivas teóricas, pois permitem visualizar os processos de construção dos significados, constituindo locais privilegiados para explorar conceitos decorridos da teoria cultural, devido à sua missão de identificar, diferenciar e classificar (Mason 2006, 22).

32 Contudo, as coleções, particularmente as coleções históricas, refletem inevitavelmente os gostos e os interesses, bem como, consequentemente, as interpretações dos seus colecionadores e raramente se constituíram com o propósito de serem totalmente representativas. De facto, Braudillard, em 1968, escreveu «It is invariably oneself that one collects» $(1968,12)$. Como resultado, por um lado, os museus possuem coleções de qualidade excecional, por outro lado, podem parecer indecifráveis a uma audiência mais vasta. Os curadores, cada vez mais com o contributo dos educadores e de outros profissionais, selecionam o que será exposto e com que propósito ou tema em mente. $O$ modo como uma seleção de objetos é exposta ao público reflete o pensamento daqueles responsáveis pelo processo, normalmente provenientes de um contexto social particular e de abordagem académica, se bem que isto esteja atualmente a mudar. Consequentemente, este tipo de exposição não comunica eficazmente com uma audiência não especializada. Os visitantes, por sua vez, trazem as suas experiências e perceções para 
a exposição, construindo variados significados pessoais que podem ser bastante diferentes das intenções dos organizadores da exposição (Lang 2006, 36).

Na sequência destas linhas de pensamento, os museus demonstram bastante interesse no processo de construção de significados pelos visitantes. Este posicionamento conduziu, inclusivamente, a novas formas de investigação. Os modelos de investigação controlada, de tipo laboratorial, utilizados para os primeiros estudos de visitantes foram substituídos por paradigmas mais naturalistas, influenciados pela sociologia e pela etnografia, bem como por uma agenda de investigação mais aberta. Neste âmbito, uma das primeiras ferramentas de análise prende-se com o estudo dos processos interpretativos utilizados pelo público museológico.

Os visitantes constroem significados utilizando uma série de estratégias interpretativas. $O$ significado criado é pessoal, relacionando-se com estruturas mentais existentes, com o padrão de ideias sobre o qual se baseiam outras interpretações das experiências ocorridas ao longo da vida. Este processo também se caracteriza por ser um processo social, pois é influenciado pela família, pares, amigos e colegas, formando uma comunidade de «criadores de significados» à qual o indivíduo pertence (Hooper-Greenhill 1996, 12). o significado construído não deixa de ser político, no sentido de que sofre a influência da classe social, do género e da etnia em que o indivíduo se posiciona.

o processo de criação de significados constitui a forma de compreender uma determinada experiência, de explicar ou interpretar o mundo para o próprio ou para outros. Nos museus, o significado é criado a partir de objetos e do local em si próprio, envolvendo um encontro entre o passado, o presente e a representação dessa realidade. 0 termo interpretação, no movimento filosófico, significa as formas como os indivíduos fazem sentido das coisas, estando este processo centrado na atividade mental do sujeito. Nos museus, no entanto, o termo possui um outro significado, sendo a sua definição bastante abrangente, mas designando também "fazer interpretação" para outros. Neste contexto, a interpretação da exposição constitui a forma como a exposição é desenhada de modo a permitir a compreensão das ideias que pretende transmitir, e, na comunicação do objeto os museus procuram criar ligações entre o objeto e o visitante através de pontos de ligação entre ambos (Hooper-Greenhill 1996, 12).

36 Neste âmbito, no museu, parte da interpretação é feita para o visitante, contudo, este não é um recetor passivo, mas conduz o seu próprio processo de construção de significados, socorrendo-se da sua experiência e contexto, bem como do seu conhecimento. Posto isto, os significados são construídos e dependem da relação entre passado e presente, possuindo a interpretação um âmbito temporal relacionado com o seu posicionamento na história e na cultura. Este processo depende das experiências anteriores de cada indivíduo, pois o conhecimento possui uma base social e cultural, que se reflete na interpretação de cada sujeito e do seu lugar no mundo. O sistema de conhecimentos construído permite que o indivíduo se insira numa determinada sociedade ou grupo, sendo possível identificar comunidades de pessoas que partilham de estratégias de interpretação. Verifica-se que a estratégia interpretativa de cada visitante determina o significado dos objetos, estabelecendo formas de olhar o mesmo (Hooper-Greenhill 1996, 14).

37 Mais recentemente, o afeto tem vindo a ser conhecido como uma importante ferramenta para alcançar a participação da audiência no processo de criar significado. No contexto museológico e expositivo, tem-se vindo a explorar a importância dos objetos pela sua capacidade de invocar memórias e envolvimento sensorial. Neste âmbito, os objetos 
expostos constituem-se como forças produtivas, capazes de acionar mecanismos de memória e de funcionar como veículos para o conhecimento. Estes abrem a possibilidade de evocação, implicando um diálogo aberto entre o objeto e o sujeito (Gregory e Witcomb 2007, 263).

Face a este cenário, os museus constituem-se como um potencial palco para a interação entre públicos e objetos, lugar de memória e identidade, que evoca estruturas narrativas diversas e provoca diferentes situações dialogantes, em que interagem conhecimentos e experiências de níveis e conteúdos vários. Os visitantes chegam aos museus com as suas agendas de aprendizagem de acordo com os conhecimentos que já possuem sobre a temática e pesando também o facto de estarem ou não na posse de uma memória coletiva (mais necessária no caso dos museus de história local).

\section{Reflexão sobre as formas de representação que ocorrem no museu}

Normalmente, os projetos de museus locais e municipais desfrutam de altos níveis de consenso e raramente atraem conflito e contestação, o que ajuda a explicar o seu papel ativo na construção e promoção de um discurso que realça a importância e relevância da cultura como símbolo do progresso e desenvolvimento local. Os museus municipais são reconhecidos pelo seu forte sentimento de apego à localidade, desempenhando um papel importante na regeneração cultural e social das localidades.

Os museus também podem propiciar novas formas de incentivar o sentimento de pertença através da criação de discursos locais. Na realidade, quando as identidades culturais e sociais se tornam incertas ou efémeras, existe um amplo leque de recursos simbólicos que podem ser utilizados na construção de novos discursos. Quando as fronteiras identitárias se tornam frágeis, indistintas e fluidas, os esforços no sentido de dotar as comunidades de autenticidade e individualidade intensificam-se, visando uma validação cultural da identidade. Neste sentido, o património é mais do que um legado do passado, assumindo o papel de produto do presente, apropriado por diferentes grupos sociais como um instrumento capaz de criar novas referências identitárias, que geram um sentido de pertença a um sítio particular. Contudo, existem riscos nesta postura que exclui, ignora e, por vezes, deprecia as novas configurações do presente. A colocação da tónica num passado imaginado, vagamente relacionado com a experiência de somente alguns pode transformar os museus locais no que Marta Anico descreve como «cofresfortes» identitários (Anico 2009, 64). De forma algo contraditória também se verifica que estes museus incorporam muitas das tendências que definem as práticas museológicas pós-modernas. Assim, constata-se que a representação do local também se socorre de uma grande diversidade de património como forma de promover um diálogo efetivo entre as culturas e grupos sociais que marcam a sua presença nos novos territórios da pósmodernidade.

Pode-se verificar que os museus são instituições relacionais, que refletem e influenciam o seu ambiente. A sua sobrevivência depende da capacidade de se adaptarem a contextos em mudança e da sua capacidade de negociarem essa mesma mudança. Isto implica a «redefinição e a reinvenção da identidade dos museus e o abandono de um conjunto obsoleto de valores herdado do seu passado institucional» (Anico 2009, 68). 

construção de novas formas de diálogo e de participação dos públicos, sendo necessária a existência de reciprocidade, constituindo-se redes de recursos e geradoras de fóruns de partilha. Neste âmbito, os museus, e principalmente os museus locais, podem, em potencial, assumir-se como um espaço de comunicação e de ação performativa. Se a necessidade de formar públicos não é contestada, as estratégias para concretizar este objetivo têm-se mostrado diversificadas, bem como o entendimento do termo, que pode ser visto sob uma perspetiva de aumento do número de visitantes ou de diversificação dos mesmos. Posto isto, constata-se a existência de formas diferenciadas de comunicar com os 
públicos, ora assentes num modelo unívoco de transmissão de conhecimentos, ora em formas mais interativas de comunicar, apelando à participação e ao envolvimento dos indivíduos (Gomes e Lourenço 2009, 22).

\section{Conclusão}

47 Os estudos de públicos incluem um crescente campo de conhecimentos empíricos sobre os visitantes e a sua interação com o museu, tendo vindo a propor modelos explicativos próprios, sustentados por teorias decorrentes de outros campos das ciências sociais e da teoria cultural. Estes estudos constituem uma disciplina aplicada, cuja metodologia provém das ciências sociais, mas que desenvolveu uma versão avaliativa própria, adaptada à complexidade e à singularidade do seu âmbito de aplicação, constituído por contextos educativos, sociais e comunicativos específicos.

48 A necessidade de aprofundar o conhecimento dos públicos das instituições decorre do reconhecimento dos museus como um tema de interesse sociológico, no âmbito da convergência entre as ciências sociais e a museologia, assumindo os museus como palco de intercâmbio de ideias sobre o mundo social. 0 significado dos museus é agora aparente no estudo das desigualdades, do turismo, da cultura popular e das representações visuais. Deste contexto decorre tanto o interesse dos sociólogos nos modos de expor a cultura, como a necessidade do corpo técnico e dos decisores dos museus refletirem sobre a mudança da ênfase do objeto alvo de curadoria para os contextos sociais e culturais que geram o significado do próprio objeto e em conhecer quem consome os significados dos museus.

49 Neste âmbito, os museus, constituem-se como ferramentas no processo de criação de significados, um veículo para a transmissão de ideias e de valores. A tomada de consciência desta realidade implica grande responsabilidade para profissionais e decisores, pois os museus, tal como o património, possuem a capacidade de negociar e criar novas identidades, valores e entendimentos, promovendo experiências culturais únicas, que permitem à sua audiência construir ativamente os seus próprios significados e interpretações.

50 Se, por um lado, os profissionais sentem o apelo e a necessidade dos museus se constituírem como um serviço orientado para o público, também se constata que para alcançar este objetivo é necessário uma melhor compreensão dos visitantes e públicos, originando o desenvolvimento de novas competências e valências profissionais dos técnicos, mas, também, o estabelecimento de novas prioridades para os recursos dos museus e de uma nova conceção das políticas e projetos museológicos.

51 O reconhecimento de que a experiência de visita constitui uma construção passível de estudo conduz a novas formas de pensar os museus. Nesta perspetiva, o visitante não se deve encontrar removido dos objetos expostos, pela distância da representação, mas imerso no tema em causa. Nas instituições surge, cada vez mais, o reconhecimento de que os museus se encontram em competição com outros espaços da indústria do lazer e que os públicos estão acostumados a um nível crescente do espetacular. Neste contexto, a informação e o conhecimento sobre os visitantes e os públicos revela-se cada vez mais necessária, continuando este cenário a expandir-se na atualidade para incluir um mundo mediado por redes de comunicação, em que o Facebook, o Twitter, o Flickr perfuram as fronteiras da exposição. Com um adequado conhecimento dos utilizadores dos museus é 
possível vir a utilizar estas ferramentas para mediar o envolvimento dos visitantes com as instituições. Neste âmbito, novas questões se levantam sobre a relação do museu com os seus públicos, sendo a única conclusão possível que, cada vez mais, os museus, precisam de encontrar estratégias para conhecerem as suas audiências e os seus visitantes, bem como a sociedade onde atuam, visando dar resposta a novos e complexos desafios, em que totais anuais de visitantes não são suficientemente esclarecedores da dinâmica dos museus, nem da complexidade dos públicos. Com as novas ferramentas de comunicação, a experiência de visita começa antes da chegada aos museus e, igualmente, não termina quando o visitante se vai embora, sendo possível a continuação da interação com o espaço museológico.

\section{BIBLIOGRAFIA}

Aibéo, Bárbara, e João Teixeira Lopes. 2007. Os Públicos da Cultura em Santa Maria da Feira. [s.l.]: Edições Afrontamento.

Anico, Marta. 2005. “A Pós-Modernização da Cultura: Património e Museus na Contemporaneidade.” Horizontes Antropológicos 11 (23). http://dx.doi.org/10.1590/ S0104-71832005000100005.

Anico, Marta. 2009. "Representing Identities at Local Municipal Museums: Cultural Forums or Identity Bunkers?" In Heritage and Identity: Engagement and Demission in the Contemporary World, editado por Marta Anico, e Elsa Peralta, 63-76. London: Routledge.

Baudrillard, Jean. 1968. "The System of Collecting." In The Cultures of Collecting, editado por John Elsner, e Roger Cardinal, 7-24. Cambridge: Harvard University Press.

Baudrillard, Jean. 1983. Simulations. New York: Semiotext(e).

Bauman, Zygmunt. 2000. Liquid Modernity. Cambridge: Policy Press.

Crooke, Elizabeth. 2007. Museums and Community: Ideas, Issues and Challenges. London: Routledge.

Davallon, Jean. 2003. “La Médiation: la Communication en Procés?" Médiation \& Information 19: 37-59. http://www.mei-info.com/wp-content/uploads/revue19/ilovepdf.com_split_3.pdf.

Davis, Peter. 2007. "Place Exploration: Museums, Identity, Community". In Museums and Their Communities, editado por Sheila Watson, 53-76. Leicester Readers in Museum Studies. London: Routledge.

Falk, John. 2009. Identity and the Museum Visitor Experience. Walnut Creek: Left Coast Press.

Featherstone, Mike. 1990. “Moderno e Pós-Moderno: Definições e Interpretações Sociológicas.” Sociologia-Problemas e Práticas 8: 93-105.

Fyfe, Gordon. 2006. "Sociology and the Social Aspects of Museums." In A Companion to Museum Studies, editado por Sharon Macdonald, 33-49. Malden e Oxford: Blackwell Publishing.

Gomes, Rui Telmo, e Vanda Lourenço. 2009. Democratização Cultural e Formação de Públicos: Inquérito aos "Serviços Educativos" em Portugal. [s.l.]: Observatório das Atividades Culturais. 
Graburn, Nelson. 2007. “A Quest for Identity.” In Museums and their Communities, editado por Sheila Watson, 127-133. Leicester Readers in Museum Studies. London: Routledge.

Gregory, Kate, e Andrea Witcomb. 2007. "Beyond Nostalgia: The Role of Affect in Generating Historical Understanding at Heritage Sites." In Museum Revolutions: How Museums Change and Are Changed, 263-275. London: Routledge.

Guillaume, Marc. 2003. A Política do Património. Porto: Campo das Letras.

Gurian, Elaine. 2005. “Threshold Fear.” In Reshaping Museum Space: Architecture, Design, Exhibitions, editado por Suzanne Macleod, 203-220. London: Routledge.

Gurian, Elaine. 2006. Civilizing the Museum: The Collected Writings of Elaine Heumann Gurian. London: Routledge.

Hooper-Greenhill, Eilean. 1996. "Communication in Theory and Practice." In The Educational Role of the Museum, editado por Eilean Hooper-Greenhill, 28-43. London: Routledge.

Hooper-Greenhill, Eilean. 1996. "Education, Communication and Interpretation: Towards a Critical Pedagogy in Museums." In The Educational Role of the Museum, editado por Eilean HooperGreenhill, 3-27. London: Routledge.

Hooper-Greenhill, Eilean. 2006. "Studying Visitors." In A Companion to Museum Studies, editado por Sharon Macdonald, 362-377. London: Blackwell Publishing.

Hooper-Greenhill, Eilean. 2007. "Interpretative Communities, Strategies and Repertoires." In Museums and Their Communities, editado por Sheila Watson, 76-95. Leicester Readers in Museum Studies. London: Routledge.

Lang, Caroline. 2006. “The Public Access Debate.” In The Responsive Museum: Working with Audiences in the Twenty-First Century, editado por Caroline Lang, John Reeve, e Vicky Woollard, 29-41. Ashgate e Burlington: Ashgate Publishing.

Lowenthal, David. 2003. The Past is a Foreign Country. 11. a ed. Cambridge: Cambridge University Press.

Lyotard, Jean-François. 1984. The Postmodern Condition: A Report on Knowledge. Minneapolis: University of Minnesota Press.

Lyotard, Jean-François. 1986-87. "Rules and Paradoxes or Svelt Appendix." Culture Critique 5: 201-215.

Macdonald, Sharon. 1996. "Cultural Imagining Among Museum Visitors." In The Educational Role of the Museum, editado por Eilean Hooper-Greenhill, 269-277. London: Routledge.

Mason, Rhiannon. 2006. "Cultural Theory and Museum Studies." A Companion to Museum Studies, editado por Sharon Macdonald, 17-32. Malden e Oxford: Blackwell Publishing.

Pearce, Susan. 1992. Museums, Objects and Collections: A Cultural Study. Leicester: Leicester University Press.

Reeve, John, e Vicky Woollard. 2006. “Influences on Museum Practice.” In The Responsive Museum: Working with Audiences in the Twenty-First Century, editado por Caroline Lang, John Reeve, e Vicky Woollard, 5-19. Ashgate e Burlington: Ashgate Publishing.

Thistlewod, David. 1993. American Abstract Expressionism. Liverpool: Liverpool University Press e Tate Gallery Liverpool.

Weil, Stephen. 2007. "The Museum and the Public." In Museums and Their Communities, editado por Sheila Watson, 32-47. Leicester Readers in Museum Studies. London: Routledge. 


\section{RESUMOS}

0 artigo procura realizar uma reflexão sobre o posicionamento dos museus na sociedade e mundo contemporâneo, influenciados pelas correntes pós-modernistas, interrogando-se sobre os públicos e os visitantes, principalmente no que concerne ao seu relacionamento com a instituição, em que são centrais questões relacionadas com as formas de representação conduzidas pelos museus e o processo de interpretação das exposições desenvolvido pelos visitantes. A partir da análise de uma seleção de bibliografia considerada relevante para os temas em análise, é efetuada uma breve contextualização sobre a sociedade contemporânea e o seu relacionamento com o universo museológico, que irá conduzir a uma série de questões/reflexões sobre os públicos, as representações e as interpretações que têm lugar nos museus. Os temas alvo de ponderação estão diretamente relacionados entre eles e participam no debate mais amplo sobre a função e o papel dos museus. Trata-se de um artigo que realiza um enquadramento sobre os pontos acima expostos e que nasce da investigação no âmbito da preparação de uma dissertação de doutoramento, num momento em que o processo de levantamento bibliográfico e de desenvolvimento do plano de investigação conduziram a uma série de interrogações e à necessidade de estabelecer um diálogo entre a prática de investigação e a de mediação na instituição museológica que é o caso de estudo.

The paper aims to reflect on the issue of museum context and position in the contemporary world, and society, as influenced by post-modern trends. The author examines audiences and visitors, their relationship with the institution, focusing in the issues that relate to the representations of the heritage promoted by the museum and the interpretative process conducted by the visitors. Following the analysis of a bibliographic selection considered relevant to the subjects presented, a brief context of contemporary society and of its relationship with the museum universe is made, leading to a series of questions/reflections about the museum audience, the representations and the interpretations that take place in the museums. The themes are directly connected to, and participate in, the wider debate on the role and function of museums. The article establishes the background for the above mentioned topics and is written in the context of the research for a doctoral thesis, at a moment when the bibliography research and development of the investigation plan led to a series of questions and to the necessity of establishing a dialogue between research practice and mediation practice in the institution serving as a case study.

\section{ÍNDICE}

Keywords: audience, visitor, representation, interpretation, visitor studies, museum Palavras-chave: público, visitante, representação, interpretação, estudo de público, museu

\section{AUTOR}

\section{ANDREIA VALE LOURENÇO}

Licenciada em História variante Arqueologia pela Faculdade de Letras da Universidade de Coimbra e mestre em Museologia e Património Cultural na mesma instituição. Atualmente, é doutoranda em Museologia na Faculdade de Letras da Universidade do Porto, sob a orientação de Alice Semedo. A sua investigação de doutoramento aborda os públicos e o processo de construção 
da motivação para a visita aos museus, tendo como estudo de caso o Museu da Cidade de Aveiro. Colabora no Museu da Cidade de Aveiro da tutela da Câmara Municipal de Aveiro.

andreia.vale.lourenco@gmail.com 